Volume 2

Issue 3 - Vascular Disease

Article 3

8-14-2015

\title{
Clinical Outcomes After Drug-Eluting Stents Versus Coronary Artery Bypass Surgery in High Surgical Risk Patients With Left Main or Three-Vessel Coronary Artery Disease
}

Tonga Nfor Kambiz Shetabi

Wael Hassan

Quinta Nfor

Jayant Khitha

Anjan Gupta

Tanvir Bajwa

Suhail Allaqaband

Follow this and additional works at: https://aah.org/jpcrr

Part of the Cardiology Commons, Cardiovascular Diseases Commons, Other Analytical, Diagnostic and Therapeutic Techniques and Equipment Commons, and the Surgical Procedures, Operative Commons

\section{Recommended Citation}

Nfor T, Shetabi K, Hassan W, Nfor Q, Khitha J, Gupta A, Bajwa T, Allaqaband S. Clinical outcomes after drug-eluting stents versus coronary artery bypass surgery in high surgical risk patients with left main or three-vessel coronary artery disease. J Patient-Centered Res Rev. 2015;2:95-103. doi: 10.17294/

2330-0698.1045

Published quarterly by Midwest-based health system Advocate Aurora Health and indexed in PubMed Central, the Journal of Patient-Centered Research and Reviews (JPCRR) is an open access, peer-reviewed medical journal focused on disseminating scholarly works devoted to improving patient-centered care practices, health outcomes, and the patient experience. 


\section{Clinical Outcomes After Drug-Eluting Stents Versus Coronary Artery Bypass Surgery in High Surgical Risk Patients With Left Main or Three-Vessel Coronary Artery Disease}

Tonga Nfor, MD, MSPH, Kambiz Shetabi, MD, Wael Hassan, MD, Quinta Nfor, MSN, Jayant Khitha, MD, Anjan Gupta, MD, Tanvir Bajwa, MD, Suhail Allaqaband, MD

Aurora Cardiovascular Services, Aurora Sinai/Aurora St. Luke's Medical Centers, University of Wisconsin School of Medicine and Public Health, Milwaukee, WI

Purpose $\quad$ Previous studies comparing percutaneous coronary intervention (PCl) with coronary artery bypass graft surgery $(C A B G)$ in patients with unprotected left main or three-vessel coronary artery disease (LM-3VD) have excluded patients at high surgical risk. We compared clinical outcomes after $\mathrm{PCl}$ with drug-eluting stents to CABG in high surgical risk patients with LM-3VD.

Methods $\quad$ Patients with symptomatic LM-3VD who had Society of Thoracic Surgeons (STS)-predicted operative mortality $>5 \%$ and were undergoing either $\mathrm{PCl}$ with drug-eluting stents or CABG at a tertiary care center from January 2009 to December 2010 were enrolled in this nonrandomized prospective study.

Results $\quad$ Mean STS score was $14.5 \pm 5.8 \%$ for $\mathrm{PCl}(\mathrm{n}=83)$ versus $13.6 \pm 7.1 \%$ for CABG $(n=187)(P=0.31)$. After mean follow-up of 37 months, incidence of the composite primary endpoint (death, myocardial infarction or stroke) was $42.2 \%$ for $\mathrm{PCl}$ and $39.6 \%$ for $\mathrm{CABG}(\mathrm{P}=0.69$, hazard ratio $1.3,95 \%$ confidence interval 0.5-2.8). There were no differences in the individual components of the primary endpoint between $\mathrm{PCl}$ and $\mathrm{CABG}$. Repeat revascularization was $30.1 \%$ for $\mathrm{PCl}$ versus $9.6 \%$ for $\mathrm{CABG}(\mathrm{P}=0.001)$. Major adverse cardiac and cerebrovascular event rates were similar between $\mathrm{PCl}$ and $\mathrm{CABG}, 50.6 \%$ versus $42.2 \%$, respectively $(\mathrm{P}=0.23)$. Patients in the $\mathrm{PCl}$ group were less likely than those in the $\mathrm{CABG}$ group to be discharged to a nursing home $(12.1 \%$ vs. $47.1 \%, \mathrm{P}<0.001)$ and had shorter hospital stays $(5.6 \pm 5.7$ days vs. $15.1 \pm 10.6$ days, $\mathrm{P}<0.001)$.

Conclusions The composite rate of death, myocardial infarction or stroke is similar for $\mathrm{PCl}$ and $\mathrm{CABG}$ in patients with symptomatic LM-3VD who have STS-predicted operative mortality $>5 \%$.

Keywords high risk, three-vessel disease, left main, Heart Team, stenting, coronary artery bypass grafting

Left main or three-vessel coronary artery disease (LM$3 \mathrm{VD}$ ) occurs in $27 \%$ of men and $8 \%$ of women older than 30 years who undergo coronary angiography for suspected coronary artery disease. ${ }^{1,2}$ Without revascularization, the prognosis is dismal, with 3-year mortality of $24 \%$ for three-vessel disease without left main disease ${ }^{3}$ and $30-50 \%$ when left main disease is present. ${ }^{4,5}$ Coronary artery bypass graft surgery $(\mathrm{CABG})$ is the traditional gold standard for revascularization of LM-3VD. ${ }^{6-10}$ Over the past decade,

Correspondence: Suhail Allaqaband, MD, 2801 W. Kinnickinnic River Parkway, Suite 840, Milwaukee, WI, 53215,

T: 414-649-3909, F: 414-649-3551, Email:

publishing3@aurora.org outcomes of percutaneous coronary intervention (PCI) in complex coronary artery disease have improved due to advances in stent design and other interventional equipment, effectiveness of pharmacotherapy and experience of operators. ${ }^{11,12}$ Recent randomized controlled trials have shown that overall major adverse cardiac and cerebrovascular events (MACCE) are lower with $\mathrm{CABG}$ than $\mathrm{PCI}$ in patients revascularized for unprotected LM-3VD. ${ }^{13-18}$ However, the outcomes of CABG and PCI were similar in patients who have focal disease with SYNTAX score $\leq 22 .{ }^{18,19}$

Due to the more invasive nature and higher shortterm morbidity of CABG, PCI has been empirically considered a good alternative to $\mathrm{CABG}$ in patients 
who are deemed a high surgical risk. In clinical practice, surgical risk is defined by different criteria including age, ${ }^{20,21}$ general frailty ${ }^{22,23}$ and surgical risk scores. $^{24,25}$ The latest guidelines for PCI recommend consideration of PCI over CABG in patients with LM-3VD who have favorable coronary anatomy for PCI when Society for Thoracic Surgeons (STS) score predicts operative mortality as $>5 \% .^{7}$ However, this threshold is arbitrary and not based on published data because high surgical risk patients were excluded from major studies comparing PCI to CABG. The aim of this study was to compare clinical outcomes after PCI with drug-eluting stents versus CABG in patients with unprotected LM-3VD who have STS-predicted operative mortality $>5 \%$.

\section{METHODS Design}

This was a nonrandomized prospective study comparing clinical outcomes between high surgical risk patients who underwent PCI versus those who underwent CABG for symptomatic LM-3VD. Local institutional review board approval and signed informed consent from the subjects were obtained for the study.

\section{Patients and Procedures}

Consecutive patients who underwent PCI with drugeluting stents or $\mathrm{CABG}$ for symptomatic unprotected LM-3VD at a single tertiary care center from January 2009 to December 2010 were included in the study if they had a baseline STS-predicted operative mortality $>5 \%$. Documentation of ischemia based on symptoms of classic angina, a positive noninvasive test, newly decreased left ventricular ejection fraction or acute coronary syndrome was required. Patients were excluded from the study if they had previously undergone $\mathrm{CABG}$ or had a concomitant cardiac pathology that needed treatment at the time of revascularization (e.g. significant valve disease). Patients also were excluded if they had an allergy to aspirin or clopidogrel.

Left main revascularization was performed for angiographic stenosis $>50 \%$ or minimal luminal area $\leq$ $6 \mathrm{~mm}^{2}$ as determined by intravascular ultrasound. Other epicardial arteries were revascularized for angiographic stenosis $>70 \%$, minimal luminal area by ultrasound $<4$ $\mathrm{mm}^{2}$ on proximal segments or fractional flow reserve $<$
0.8. The choice of revascularization method was at the discretion of the treating physicians and their patients, usually with collaboration from our institution's multidisciplinary Heart Team. Periprocedural therapies and maintenance treatments were provided according to standard clinical guidelines.

\section{Data Collection}

A previously tested and validated data collection questionnaire was used to extract data from patients' electronic medical records. Baseline sociodemographic and clinical comorbidities as well as indications for revascularization were recorded. Information on equipment used, medications given and grafts used were obtained from procedural reports and case documents. Angiograms were reviewed by two independent cardiologists, and SYNTAX scores were calculated using the online SYNTAX Score Calculator ${ }^{\circledR}$, Version 2.1 (www.syntaxscore.com). ${ }^{26}$ Surgical risk scores were calculated for all patients using the online logistic EuroSCORE calculator (www.euroscore.org/calc. html) ${ }^{27}$ as well as the STS Risk Calculator (riskcalc. sts.org/STSWebRiskCalc273/). ${ }^{28}$

\section{Endpoints}

Endpoints were identified by reviewing data from patients' medical records. Patients who had no follow-up records were called for a phone interview to inquire about cardiac events. The primary endpoint was a composite of death from any cause, myocardial infarction or stroke, whichever occurred first. Individual secondary endpoints were myocardial infarction, stroke, death from any cause and ischemiadriven repeat revascularization. MACCE constituted a composite secondary endpoint comprising the four individual secondary endpoints. Myocardial infarction was defined as a rise and fall in troponin associated with ischemic symptoms, new ischemic changes on electrocardiogram, new regional wall motion abnormalities or loss of viable myocardium on imaging. Stroke was defined as a new focal neurological deficit lasting $>24$ hours or radiological evidence of acute cerebral infarction or hemorrhage. Repeat revascularization was defined as any subsequent PCI or $\mathrm{CABG}$ after the index procedure that was performed for definite angina, worsening cardiomyopathy, abnormal noninvasive study or acute coronary syndromes. Outof-hospital deaths were identified through the National 


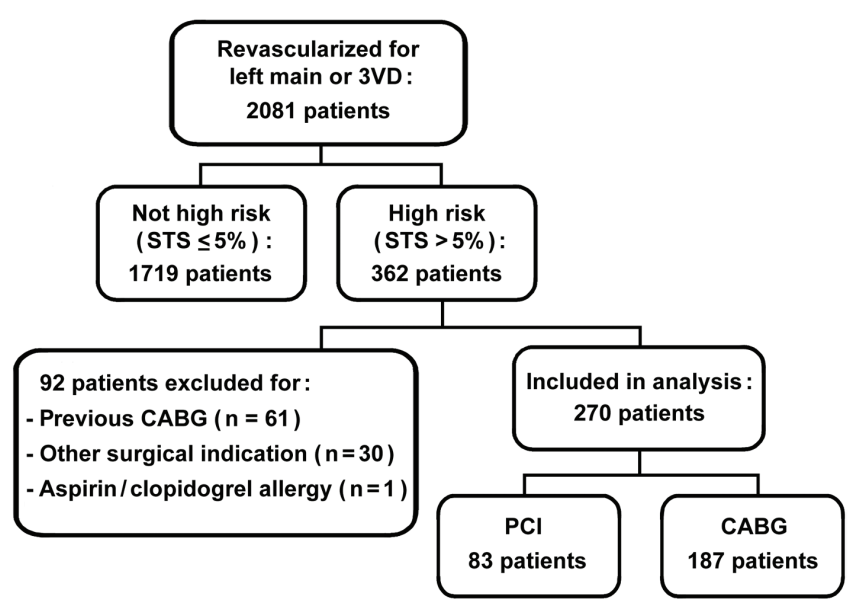

Figure 1. Study population flow chart. $3 V D$, three-vessel coronary artery disease; CABG, coronary artery bypass graft surgery; $\mathrm{PCl}$, percutaneous coronary intervention; STS, Society of Thoracic Surgeons.

Death Index. Follow-up time was counted from the date of index revascularization.

\section{Statistical Analyses}

Summary descriptive statistics for continuous variables were expressed as means ( \pm standard deviation), and univariate comparisons were made between PCI and $\mathrm{CABG}$ groups using the Mann-Whitney $U$ test. Categorical variables were reported as percentages and compared using Fisher's exact test. Treatment selection bias was overcome by using propensity-matched analysis. A propensity score was calculated for each patient using multivariate binary logistic regression, which was calculated as the probability of undergoing PCI (rather than CABG) as predicted by baseline characteristics, namely age, sex, race, cardiac risk factors, comorbidities, acuity of clinical presentation, presence of left main disease and SYNTAX score. Cumulative event rates were compared using KaplanMeier analysis and the log-rank test. Hazard ratios with $95 \%$ confidence intervals (CI) were calculated by multivariate Cox regression adjusting for propensity score, STS score, SYNTAX score and left main disease. We assessed the model for overfitting by tracking the trend in the adjusted $\mathrm{R}^{2}$-values and deterioration in the P-values of regression coefficients. Prespecified stratified analyses were performed to determine subgroup differences. All P-values were two-sided.

\section{RESULTS}

Of 362 patients revascularized for LM-3VD with a baseline STS score $>5 \%, 92$ patients were excluded (Figure 1). The mean age in our final study sample $(n=270)$ was $77 \pm 9$ years, and $44 \%$ were women. Patients $\geq 80$ years old made up $41.9 \%$ of the study. There was high prevalence of comorbidities in both study groups (Table 1). The high-risk profile of the study sample is illustrated by the mean STS score of $13.9 \pm 6.8 \%$. There were $39.6 \%$ of patients with an STS score $\geq 15$, which is considered extreme risk. Although there was no difference in the mean STS score between PCI and CABG, more patients revascularized with PCI fell in this extreme risk category $(63.9 \%$ vs. $28.9 \%$, $\mathrm{P}<0.001)$. There was no significant difference in SYNTAX score and number of lesions between the PCI and CABG groups, but left main disease was more common in the PCI group while the average number of arteries revascularized was greater in the $\mathrm{CABG}$ group. Other baseline characteristics were similarly distributed between the two groups.

All patients were followed for at least 24 months, with a total mean follow-up of 37 months (range: 24-49 months). There was complete verification of all primary endpoints. Figure 2 shows Kaplan-Meier curves for survival free of the primary endpoint (i.e. composite death, myocardial infarction or stroke). Although there was no significant difference in the incidence of the primary endpoint between both groups, there seemed to be a biphasic trend for lower (but not statistically significant) incidence in the PCI group during the first 9 months and then lower in the CABG group after 9 months. The 1-month incidence of the primary endpoint was $14.5 \%$ for PCI versus $19.3 \%$ for CABG $(\mathrm{P}=0.39)$. The incidence of the primary endpoint at the end of the 3.1-year study period was $42.2 \%$ for PCI versus $39.6 \%$ for $\mathrm{CABG}(\mathrm{P}=0.69$, hazard ratio: 1.3, 95\% CI: 0.5-2.8). We performed further analysis to compare the primary endpoint between PCI and CABG within subgroups of patients defined by the presence of predictors of adverse outcomes at baseline (Figure 3). There was no difference in the primary endpoint between PCI and CABG among patients who had left main disease or three-vessel disease. There also was no significant interaction between method of revascularization and either STS score, age, diabetes, previous cardiothoracic surgery, left ventricular ejection fraction or SYNTAX score. 
Table 1. Baseline patient characteristics

\begin{tabular}{|c|c|c|c|}
\hline Variable & $\mathrm{PCl}(\mathrm{n}=83)$ & CABG $(n=187)$ & $P$ \\
\hline Age, years & $76.5 \pm 9$ & $77 \pm 9.6$ & 0.71 \\
\hline Women & 41.0 & 44.9 & 0.55 \\
\hline White & 78.3 & 85.6 & 0.16 \\
\hline Diabetes mellitus & 50.6 & 42.2 & 0.21 \\
\hline Smoker & 51.8 & 50.3 & 0.89 \\
\hline Chronic lung disease & 46.3 & 36.8 & 0.17 \\
\hline Renal failure* & 23.2 & 24.7 & 0.78 \\
\hline Prior PCl & 45.8 & 26.2 & 0.001 \\
\hline Prior cardiothoracic surgery ${ }^{\dagger}$ & 60.2 & 20.3 & $<0.001$ \\
\hline LVEF $\leq 30 \%$ & 18.1 & 23.5 & 0.32 \\
\hline \multicolumn{4}{|l|}{ Clinical presentation } \\
\hline STEMI & 9.6 & 8.6 & 0.82 \\
\hline Non-STEMI/unstable angina & 33.7 & 30.5 & 0.67 \\
\hline Stable coronary disease & 56.6 & 60.9 & 0.51 \\
\hline STS score & $14.5 \pm 5.8$ & $13.6 \pm 7.1$ & 0.31 \\
\hline EuroSCORE & $21.8 \pm 14$ & $19.8 \pm 15$ & 0.24 \\
\hline SYNTAX score & $37.0 \pm 12$ & $40.0 \pm 15$ & 0.12 \\
\hline Left main disease & 62.6 & 39.6 & $<0.001$ \\
\hline Three-vessel disease & 73.5 & 84.0 & 0.06 \\
\hline Number of arteries§ & $2.5 \pm 0.7$ & $2.9 \pm 0.3$ & 0.001 \\
\hline Number of lesions & $4.5 \pm 2$ & $4.8 \pm 1.1$ & 0.35 \\
\hline \multicolumn{4}{|l|}{ Discharge medications } \\
\hline Aspirin & 92.8 & 90.3 & 0.18 \\
\hline P2Y12 inhibitor & 95.2 & 14.4 & $<0.001$ \\
\hline Beta blocker & 81.9 & 75.4 & 0.31 \\
\hline Statin & 85.5 & 75.4 & 0.08 \\
\hline ACEI/ARB & 54.2 & 25.7 & 0.001 \\
\hline Internal mammary artery used & & 92.5 & \\
\hline Number of grafts per patient & & $2.7 \pm 0.8$ & \\
\hline Off-pump surgery & & 4.3 & \\
\hline \multicolumn{4}{|l|}{ Stent type } \\
\hline Everolimus-eluting & 59.0 & & \\
\hline Zotarolimus-eluting & 21.7 & & \\
\hline Sirolimus-eluting & 18.1 & & \\
\hline Paclitaxel-eluting & 1.2 & & \\
\hline
\end{tabular}

Values are percentage or mean \pm standard deviation.

${ }^{*}$ Creatinine $>2 \mathrm{mg} / \mathrm{dL}$.

${ }^{\dagger}$ Noncoronary cardiothoracic surgery like valves, structural heart disease, thoracic aorta, etc.

$\$$ Grouped by main arteries - right coronary, left main, left anterior descending and left circumflex.

$A C E I$, angiotensin-converting enzyme inhibitor; $A R B$, angiotensin receptor blocker; $C A B G$, coronary artery bypass graft surgery; LVEF, left ventricular ejection fraction; PCI, percutaneous coronary intervention; STEMI, ST-segment elevation myocardial infarction; STS, Society of Thoracic Surgeons. 
Table 2. Three-year outcomes of high surgical risk patients with left main or three-vessel coronary artery disease after revascularization

\begin{tabular}{lcccc}
\hline & $\begin{array}{c}\mathrm{PCl} \\
(\mathrm{n}=83)\end{array}$ & $\begin{array}{c}\mathrm{CABG} \\
(\mathrm{n}=187)\end{array}$ & $P^{*}$ & $\begin{array}{c}\text { Adjusted hazard ratio } \\
(95 \% \mathrm{Cl})\end{array}$ \\
\hline Death, MI or stroke & $42.2 \%$ & $39.6 \%$ & 0.69 & $1.3(0.5-2.8)$ \\
Death & $36.1 \%$ & $32.1 \%$ & 0.57 & $1.5(0.4-3.0)$ \\
Acute MI & $4.9 \%$ & $4.4 \%$ & 0.96 & $1.1(0.6-1.9)$ \\
Stroke & $4.9 \%$ & $8.2 \%$ & 0.44 & $0.7(0.2-1.5)$ \\
Repeat revascularization & $30.1 \%$ & $9.6 \%$ & 0.001 & $3.1(1.6-9.1)$ \\
MACCE & $50.6 \%$ & $42.2 \%$ & 0.23 & $1.7(0.7-7.2)$ \\
\hline
\end{tabular}

${ }^{*}$ Calculated using Fisher's exact test.

tHazard ratio compares PCI vs. CABG adjusted for propensity score, baseline comorbidities, Society of Thoracic Surgeons score, SYNTAX score and left main disease.

$C A B G$, coronary artery bypass graft surgery; $\mathrm{Cl}$, confidence interval; MACCE, major adverse cardiac and cerebrovascular event (death, Ml, stroke or repeat revascularization); MI, myocardial infarction; PCl, percutaneous coronary intervention.

Comparisons of secondary endpoints are shown in Table 2. Over the study period the rates of the individual endpoints of death, myocardial infarction and stroke were similar between PCI and CABG. The 30 -day mortality was $12.1 \%$ for PCI versus $14.4 \%$ for $\mathrm{CABG}(\mathrm{P}=0.70)$. Because our data sources were unreliable in correctly identifying the cause of death, we could not accurately specify cardiac mortality. The incidence of stroke was lower for PCI than CABG during the first year of follow-up only; the difference was not significant thereafter. Stroke rates were 1.2\% for PCI versus $7.5 \%$ for $\mathrm{CABG}$ at 30 days $(\mathrm{P}=0.038)$, and $2.4 \%$ versus $8.0 \%$, respectively, at 1 year $(\mathrm{P}=0.08)$. Unfortunately, the databases we accessed did not have follow-up tracking of stroke or residual disability out to 3 years. Repeat revascularization was the only clinical event with a significant difference. The rate of repeat revascularization was three times greater for PCI than CABG. All repeat revascularizations were performed by PCI. Putting all four individual endpoints together, the rate of MACCE was similar between PCI and CABG over 3.1 years.

We used length of stay as a surrogate for resource utilization during the index hospitalization. Both median length of stay in the intensive care unit and total hospital length of stay were significantly shorter for PCI than CABG (Figure 4). The mean intensive care unit stay was $2.1 \pm 3.6$ days for PCI versus $7.4 \pm 8.8$ days for $\mathrm{CABG}$, a mean difference of 5.3 days $(95 \% \mathrm{CI}$ : $3.8-6.8, \mathrm{P}<0.001)$. The mean total length of stay during

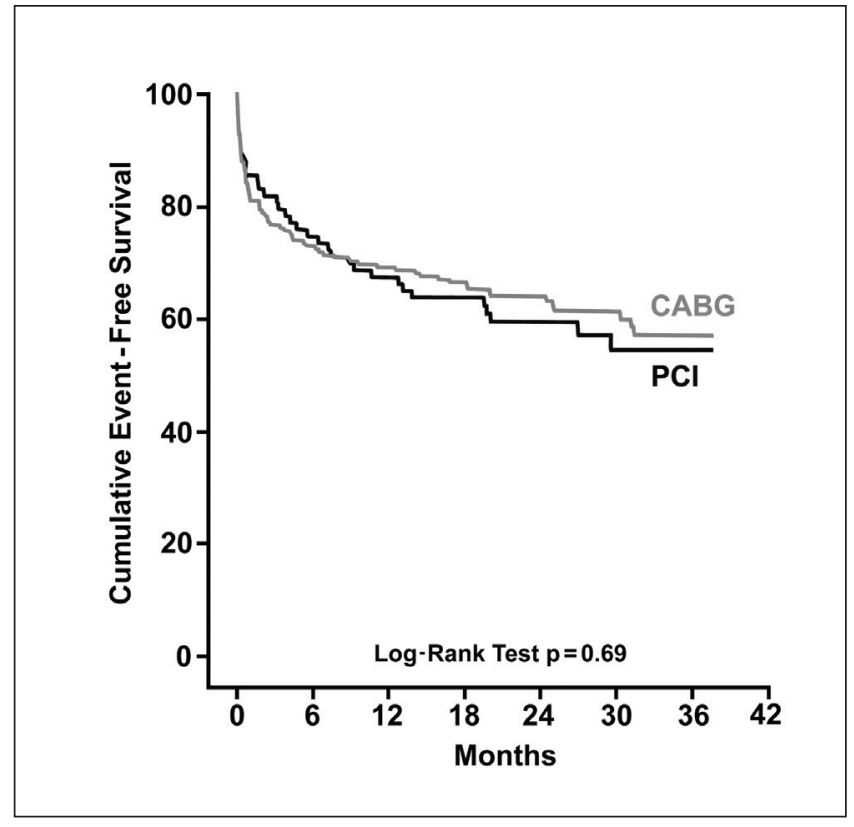

Figure 2. Kaplan-Meier curves for survival free of the primary endpoint (death, myocardial infarction or stroke) in high surgical risk patients treated with percutaneous coronary intervention (PCI) or coronary artery bypass graft surgery (CABG).

index hospitalization was $5.6 \pm 5.7$ days for PCI versus $15.1 \pm 10.6$ days for $\mathrm{CABG}$, a mean difference of 9.5 days (95\% CI: 7.6-11.5, $\mathrm{P}<0.001$ ). We also compared discharge destinations between the PCI and CABG groups. In the PCI group $85.5 \%$ were discharged home and $12.1 \%$ went to a specialized nursing/rehabilitation facility versus $41.7 \%$ going home and $47.1 \%$ going to a 


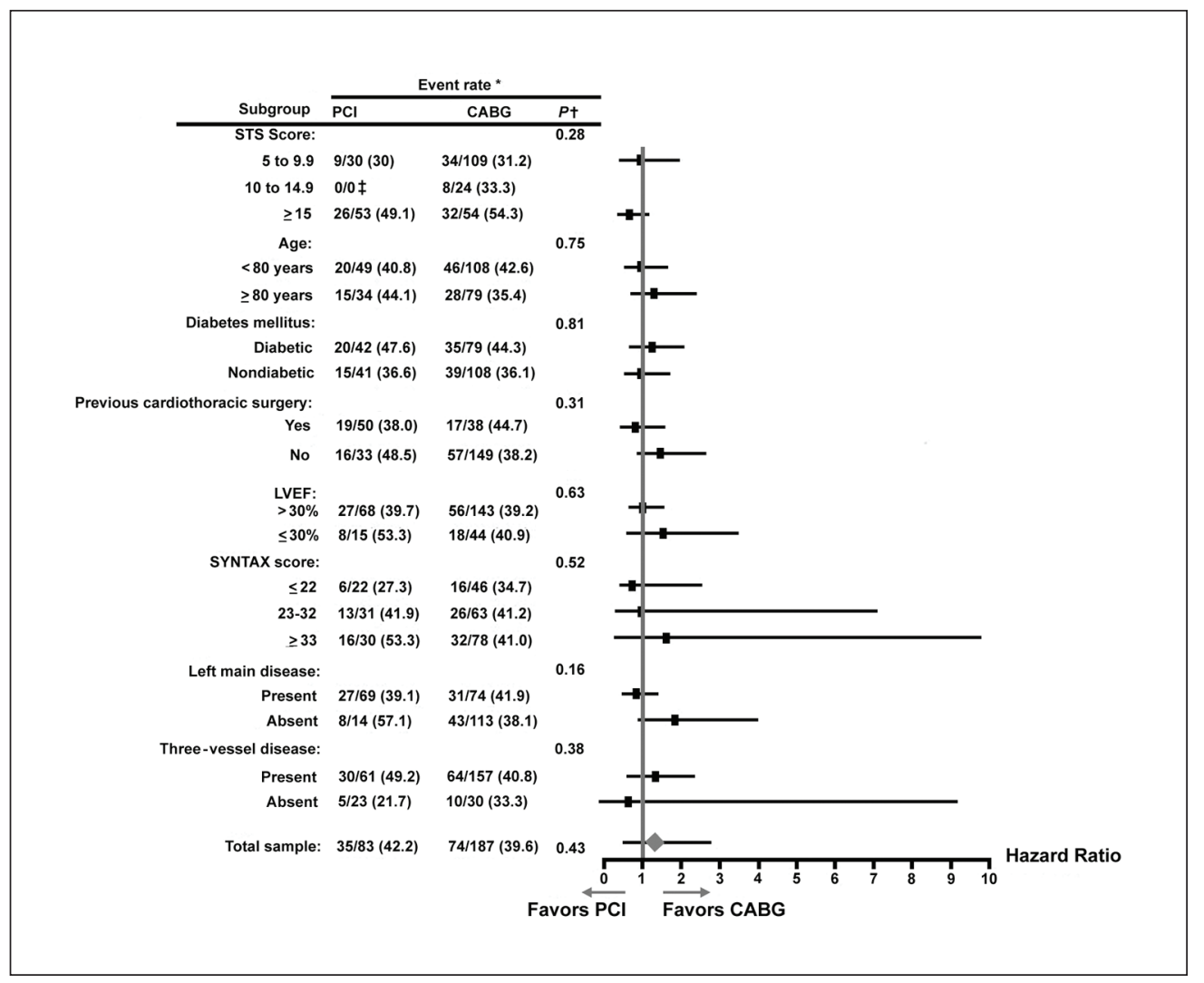

Figure 3. Multivariate Cox regression analysis within subgroups of patients comparing combined outcome of death, myocardial infarction or stroke in high surgical risk patients revascularized with percutaneous coronary intervention (PCl) or coronary artery bypass graft surgery (CABG). *Event rates are expressed as number of events/number of patients at risk (percentage). $+P$-value for interaction. $¥$ No patients in subgroup, hence P-value calculated from other two subgroups. LVEF, left ventricular ejection fraction; STS, Society of Thoracic Surgeons.

specialized nursing/rehabilitation facility after CABG $(\mathrm{P}<0.0001)$. Two patients $(2.4 \%)$ from the PCI group died in the hospital, whereas 21 patients $(11.2 \%)$ from the $\mathrm{CABG}$ group died in the hospital $(\mathrm{P}=0.017)$.

\section{DISCUSSION}

We performed a nonrandomized prospective study to compare the outcomes of PCI using drug-eluting stents and $\mathrm{CABG}$ in patients with unprotected LM3VD who had baseline STS-predicted operative mortality $>5 \%$. Over a mean follow-up period of 3.1 years the composite primary endpoint of death, myocardial infarction or stroke occurred in $42.2 \%$ of PCI patients and $39.6 \%$ of CABG patients $(\mathrm{P}=0.69)$. There was no difference in the primary endpoint among subgroups of patients with left main disease and those with three-vessel disease. The respective individual endpoints were similar between PCI and CABG. Repeat revascularization was more than three times more likely in PCI than CABG but did not lead to a higher rate of MACCE. Length of intensive care unit stay and total duration of index hospitalization was significantly longer for CABG than PCI. Patients treated with $\mathrm{CABG}$ were nearly four times more likely to be discharged to a specialized nursing facility than those treated with PCI.

This is the first study to directly compare PCI and CABG in high surgical risk patients. In the SYNTAX trial, the mean EuroSCORE-predicted mortality among randomized patients was $3.8 \pm 2.6 \% .{ }^{14}$ Even in the PCI registry arm, where patients were enrolled due to high surgical risk, the mean EuroSCORE was only $5.8 \pm$ $3.1 \% .{ }^{14}$ In the LE MANS registry of patients with left main disease treated by PCI, the mean EuroSCORE was $6.0 \pm 2.8 \%$, and the observed mortality and MACCE rates were $13.9 \%$ and $25.4 \%$, respectively, after a mean follow-up of 3.8 years. ${ }^{29}$ The mean EuroSCORE in our study was $21.8 \%$. Advanced age is one of the most important surgical risk factors. In a nonrandomized study of 249 patients $\geq 80$ years old that compared PCI to CABG in patients with unprotected left main disease, there was no difference in rates of MACCE between PCI (43.3\%) and CABG (35.2\%) after a mean follow-up of about 2 years (hazard ratio: 1.11, 95\% CI: $0.59-2.0) .{ }^{30}$ About $20 \%$ of these patients had 
concomitant three-vessel disease. Although this study included patients based on only one component of surgical risk, the findings were similar to our study.

High surgical risk patients with LM-3VD present a clinical dilemma. The decision of how to revascularize these patients is even more difficult when SYNTAX score is high. The importance of managing these patients using a comprehensive Heart Team approach cannot be overemphasized. ${ }^{7,8,31}$ The mortality rate is high in patients with multiple comorbidities who are not revascularized; however, our study shows high mortality even after either surgical or percutaneous revascularization. This finding underscores the importance of taking into account the overall prognosis when considering revascularization in high-risk patients. Our subgroup analysis showed no difference between PCI and CABG irrespective of SYNTAX or STS score category, but the subgroup numbers are too small to draw conclusions. Modifications have been proposed to reduce operative mortality and morbidity in these high-risk patients. Off-pump CABG may reduce operative complications and mortality compared to on-pump CABG, but may not be suitable for complex coronary anatomies. ${ }^{32}$ Hybrid coronary revascularization is another alternative to traditional CABG or PCI alone in high-risk patients. Surgery is done to graft an internal mammary artery to the left anterior descending artery, then PCI is performed on other coronary arteries. ${ }^{33}$ Small nonrandomized studies comparing hybrid revascularization to traditional CABG have shown similar short-term results, but long-term outcomes are unknown. ${ }^{33,34}$ An appropriate discussion to have is when revascularization should be attempted in high-risk patients and how highrisk revascularization compares to optimal medical treatment alone. A third treatment arm of optimal medical therapy would have been informative; unfortunately, such a group with sufficient follow-up data could not be identified for this study.

There are some limitations to our study. Our definition of high surgical risk as STS-predicted mortality $>5 \%$ may not be acceptable to everyone. However, this is the value used to quantify high surgical risk in the $2011 \mathrm{PCI}$ guidelines. $^{7}$ The STS score ${ }^{28}$ and EuroSCORE ${ }^{27}$ are the two most commonly used and best validated tools to quantify surgical risk in patients undergoing open heart

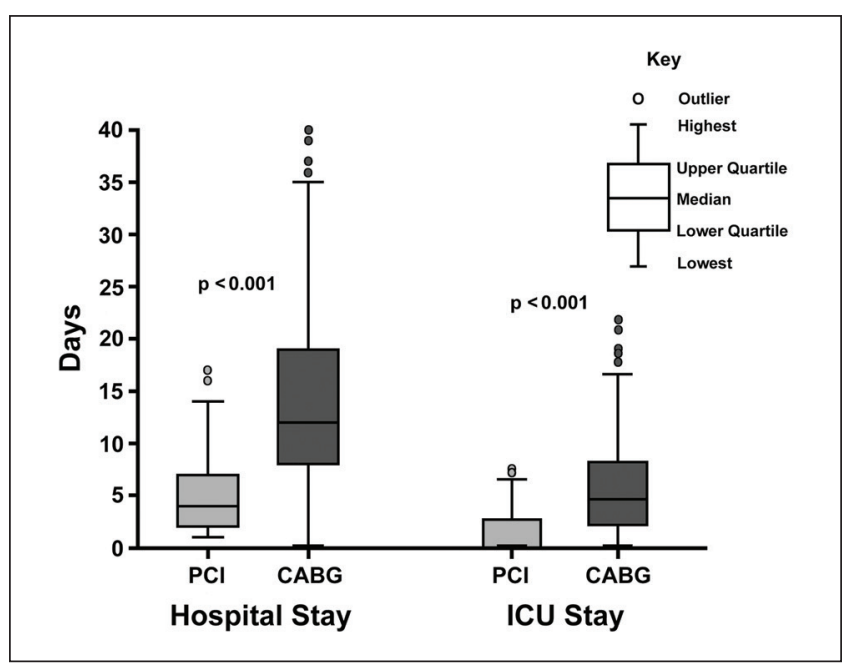

Figure 4. Total hospital and intensive care unit (ICU) stays in high surgical risk patients revascularized with percutaneous coronary intervention (PCI) or coronary artery bypass graft surgery (CABG) for left main or three-vessel coronary artery disease.

surgery. Both scores have good predictive accuracy for operative mortality, but STS score may perform slightly better than EuroSCORE. ${ }^{35}$ Newer scoring methods for PCI that add clinical variables to angiographic characteristics, like the "clinical SYNTAX score" and the "SYNTAX II score," have shown better accuracy than the angiographic SYNTAX score used in this study in predicting adverse events..$^{36,37}$ Unfortunately, unlike the angiographic SYNTAX score, these newer scores have not been tested in a study on CABG patients and have not made it into routine clinical practice. In our study it was not entirely clear for all patients how decisions were made to undergo one method of revascularization versus the other. A formal surgical consult was documented in only 45 of the 83 patients treated by PCI. Counting CABG patients, this means 232 (86\%) out of all 270 patients were officially assessed by the Heart Team comprised of a surgeon and cardiologist. We believe this study reflects real-life practice in which the cardiologist and patient together decide to skip the surgical consult when there is a strong preference for PCI by the patient. However, it is important to reemphasize here the necessity of a proper Heart Team consultation. ${ }^{7,8,31}$ Third, our study demonstrated greater upfront resource use and shortterm morbidity (based on length of stay and discharge to specialized nursing facility) after CABG than PCI 
in high surgical risk patients with LM-3VD. We, however, did not integrate actual cost data and cannot conclude that any initial cost savings will translate into long-term cost benefit given the greater need for repeat revascularization in the PCI group. Lastly, our study represents the experience of a single center and was not randomized. Our sample size may also be too small to draw definite conclusions.

\section{CONCLUSIONS}

In patients with unprotected left main or three-vessel coronary artery disease who have an STS-predicted operative mortality $>5 \%$, the combined rate of death, myocardial infarction or stroke is similar in those revascularized by percutaneous coronary intervention with drug-eluting stents or coronary artery bypass graft surgery. PCI was associated with a higher rate of repeat revascularization than $\mathrm{CABG}$, but this did not translate into a higher rate of major adverse cardiac and cerebrovascular events. Compared to patients who underwent CABG, those who underwent PCI had shorter intensive care unit and hospital stays and were also more likely to be discharged home as opposed to a specialized nursing facility. PCI may be the preferred method of myocardial revascularization over CABG in high surgical risk patients with left main or threevessel coronary artery disease due to its lower early morbidity but similar long-term clinical outcomes.

\section{Patient-Friendly Recap}

- As clinical techniques and technology advance, standard treatment recommendations must be continuously reviewed and updated.

- Patients with coronary artery disease in whom bypass surgery is deemed high risk may be better served by a less invasive revascularization procedure, called PCI, that uses drug-eluting stents to improve blood flow.

- The authors compared this type of PCI to surgery in high-risk patients and found similar success rates between the two.

- They also noted that patients who undergo PCI are able to leave the hospital sooner but require a future procedure more often than their counterparts who undergo surgery.

\section{Acknowledgments}

The authors gratefully acknowledge Brian Miller and Brian Schurrer of Aurora Sinai Medical Center for their help with figures.

\section{Conflicts of Interest}

None.

\section{REFERENCES}

1. Chaitman BR, Bourassa MG, Davis K, et al. Angiographic prevalence of high-risk coronary artery disease in patient subsets (CASS). Circulation. 1981;64:360-7. CrossRef

2. Sukhija R, Yalamanchili K, Aronow WS. Prevalence of left main coronary artery disease, of three- or four-vessel coronary artery disease, and of obstructive coronary artery disease in patients with and without peripheral arterial disease undergoing coronary angiography for suspected coronary artery disease. Am J Cardiol. 2003;92:304-5. CrossRef

3. Mock MB, Ringqvist I, Fisher LD, et al. Survival of medically treated patients in the coronary artery surgery study (CASS) registry. Circulation. 1982;66:562-8. CrossRef

4. Taylor HA, Deumite NJ, Chaitman BR, Davis KB, Killip T, Rogers WJ. Asymptomatic left main coronary artery disease in the Coronary Artery Surgery Study (CASS) registry. Circulation. 1989;79:1171-9. $\underline{\text { CrossRef }}$

5. Caracciolo EA, Davis KB, Sopko G, et al. Comparison of surgical and medical group survival in patients with left main coronary artery disease. Long-term CASS experience. Circulation. 1995;91:2325-34. CrossRef

6. Task Force on Myocardial Revascularization of the European Society of Cardiology (ESC) and the European Association for Cardio-Thoracic Surgery (EACTS); European Association for Percutaneous Cardiovascular Interventions (EAPCI), Wijns W, et al. Guidelines on myocardial revascularization. Eur Heart J. 2010;31:2501-55. CrossRef

7. Levine GN, Bates ER, Blankenship JC, et al. 2011 ACCF/AHA/SCAI Guideline for Percutaneous Coronary Intervention: a report of the American College of Cardiology Foundation/American Heart Association Task Force on Practice Guidelines and the Society for Cardiovascular Angiography and Interventions. Circulation. 2011;124:e574651. Erratum in: Circulation. 2012;125:e412. Dosage error in article text. CrossRef

8. Hillis LD, Smith PK, Anderson JL, et al. 2011 ACCF/AHA Guideline for Coronary Artery Bypass Graft Surgery: a report of the American College of Cardiology Foundation/American Heart Association Task Force on Practice Guidelines. Circulation. 2011;124:e652-735. Erratum in: Circulation. 2011;124:e957. CrossRef

9. Fajadet J, Chieffo A. Current management of left main coronary artery disease. Eur Heart. J 2012;33:36-50b. CrossRef

10. Patel MR, Dehmer GJ, Hirshfeld JW, Smith PK, Spertus JA. ACCF/SCAI/STS/AATS/AHA/ASNC/HFSA/SCCT 2012 Appropriate use criteria for coronary revascularization focused update. J Am Coll Cardiol. 2012;59:857-81. Erratum in: J Am Coll Cardiol. 2012;59:1336. CrossRef

11. Holmes DR Jr, Williams DO. Catheter-based treatment of coronary artery disease: past, present, and future. Circ 
Cardiovasc Interv. 2008;1:60-73. CrossRef

12. Brar SS, Stone GW. Advances in percutaneous coronary intervention. Curr Cardiol Rep. 2009;11:245-51. CrossRef

13. Daemen J, Boersma E, Flather M, et al. Long-term safety and efficacy of percutaneous coronary intervention with stenting and coronary artery bypass surgery for multivessel coronary artery disease: a meta-analysis with 5-year patient-level data from the ARTS, ERACI-II, MASS-II, and SoS trials. Circulation. 2008;118:1146-54. CrossRef

14. Serruys PW, Morice MC, Kappetein AP, et al. Percutaneous coronary intervention versus coronary-artery bypass grafting for severe coronary artery disease. $N$ Engl $J$ Med. 2009;360:961-72. Erratum in: N Engl J Med. 2013;368:584. CrossRef

15. Hlatky MA, Boothroyd DB, Bravata DM, et al. Coronary artery bypass surgery compared with percutaneous coronary interventions for multivessel disease: a collaborative analysis of individual patient data from ten randomised trials. Lancet. 2009;373:1190-7. CrossRef

16. Park SJ, Kim YH, Park DW, et al. Randomized trial of stents versus bypass surgery for left main coronary artery disease. $N$ Engl J Med. 2011;364:1718-27. CrossRef

17. Kajimoto K, Miyauchi K, Yamamoto T, Daida H, Amano A. Meta-analysis of randomized controlled trials on the treatment of unprotected left main coronary artery disease: oneyear outcomes with coronary artery bypass grafting versus percutaneous coronary artery intervention with drug-eluting stent. J Card Surg. 2012;27:152-7. CrossRef

18. Kappetein AP, Head SJ, Morice MC, et al. Treatment of complex coronary artery disease in patients with diabetes: 5 -year results comparing outcomes of bypass surgery and percutaneous coronary intervention in the SYNTAX trial. Eur J Cardiothorac Surg. 2013;43:1006-13. CrossRef

19. Capodanno D, Capranzano P, Di Salvo ME, et al. Usefulness of SYNTAX score to select patients with left main coronary artery disease to be treated with coronary artery bypass graft. JACC Cardiovasc Interv. 2009;2:731-8. CrossRef

20. Tuman KJ, McCarthy RJ, Najafi H, Ivankovich AD. Differential effects of advanced age on neurologic and cardiac risks of coronary artery operations. J Thorac Cardiovasc Surg. 1992;104:1510-7.

21. Peterson ED, Cowper PA, Jollis JG, et al. Outcomes of coronary artery bypass graft surgery in 24,461 patients aged 80 years or older. Circulation. 1995;92:II85-91. CrossRef

22. Lee DH, Buth KJ, Martin BJ, Yip AM, Hirsch GM. Frail patients are at increased risk for mortality and prolonged institutional care after cardiac surgery. Circulation. 2010;121:973-8. CrossRef

23. Sündermann S, Dademasch A, Praetorius J, et al. Comprehensive assessment of frailty for elderly high-risk patients undergoing cardiac surgery. Eur J Cardiothorac Surg. 2011;39:33-7. CrossRef

24. Nashef SA, Roques F, Michel P, Gauducheau E, Lemeshow $\mathrm{S}$, Salamon R. European system for cardiac operative risk evaluation (EuroSCORE). Eur J Cardiothorac Surg. 1999;16:9-13. CrossRef

25. Ferguson TB Jr, Hammill BG, Peterson ED, DeLong ER, Grover FL; STS National Database Committee. A decade of change--risk profiles and outcomes for isolated coronary artery bypass grafting procedures, 1990-1999: a report from the STS National Database Committee and the Duke Clinical Research Institute. Society of Thoracic Surgeons. Ann Thorac Surg. 2002;73:480-9; discussion 489-90. CrossRef

26. Serruys PW, Onuma Y, Garg S, et al. Assessment of the SYNTAX score in the Syntax study. EuroIntervention. 2009;5:50-6. CrossRef

27. Roques F, Michel P, Goldstone AR, Nashef SA. The logistic EuroSCORE. Eur Heart J. 2003;24:881-2. CrossRef

28. Shahian DM, O'Brien SM, Filardo G, et al. The Society of Thoracic Surgeons 2008 cardiac surgery risk models: part 1--coronary artery bypass grafting surgery. Ann Thorac Surg. 2009;88:S2-22. CrossRef

29. Buszman PE, Buszman PP, Kiesz RS, et al. Early and longterm results of unprotected left main coronary artery stenting: the LE MANS (Left Main Coronary Artery Stenting) registry. J Am Coll Cardiol. 2009;54:1500-11. CrossRef

30. Rodés-Cabau J, Deblois J, Bertrand OF, et al. Nonrandomized comparison of coronary artery bypass surgery and percutaneous coronary intervention for the treatment of unprotected left main coronary artery disease in octogenarians. Circulation. 2008;118:2374-81. $\underline{\text { CrossRef }}$

31. Task Force on Myocardial Revascularization of the European Society of Cardiology (ESC) and the European Association for Cardio-Thoracic Surgery (EACTS); European Association for Percutaneous Cardiovascular Interventions (EAPCI), Kolh $\mathrm{P}$, et al. Guidelines on myocardial revascularization. Eur $J$ Cardiothorac Surg. 2010;38 Suppl:S1-S52. CrossRef

32. Al-Ruzzeh S, Nakamura K, Athanasiou T, et al. Does offpump coronary artery bypass (OPCAB) surgery improve the outcome in high-risk patients?: a comparative study of 1398 high-risk patients. Eur J Cardiothorac Surg. 2003;23:50-5. CrossRef

33. Halkos ME, Vassiliades TA, Douglas JS, et al. Hybrid coronary revascularization versus off-pump coronary artery bypass grafting for the treatment of multivessel coronary artery disease. Ann Thorac Surg. 2011;92:1695-1701; discussion 1701-2. CrossRef

34. Bonatti JO, Zimrin D, Lehr EJ, et al. Hybrid coronary revascularization using robotic totally endoscopic surgery: perioperative outcomes and 5-year results. Ann Thorac Surg. 2012;94:1920-6; discussion 1926. CrossRef

35. Ad N, Barnett SD, Speir AM. The performance of the EuroSCORE and the Society of Thoracic Surgeons mortality risk score: the gender factor. Interact Cardiovasc Thorac Surg. 2007;6:192-5. CrossRef

36. Capodanno D, Caggegi A, Miano M, et al. Global risk classification and clinical SYNTAX (synergy between percutaneous coronary intervention with TAXUS and cardiac surgery) score in patients undergoing percutaneous or surgical left main revascularization. JACC Cardiovasc Interv. 2011;4:287-97. CrossRef

37. Farooq V, van Klaveren D, Steyerberg EW, et al. Anatomical and clinical characteristics to guide decision making between coronary artery bypass surgery and percutaneous coronary intervention for individual patients: development and validation of SYNTAX score II. Lancet. 2013;381:639-50. CrossRef

(C) 2015 Aurora Health Care, Inc. 